\title{
Approach on High Electric Fields for Remedying the Micro-Organisms Attack on Crops
}

\author{
Rwamurangwa $\mathrm{E}^{1 *}$ and Mugisha $\mathrm{PO}^{2}$ \\ 1Department of Electrical, Electronics and Computer, University of Oviedo, Spain \\ 2Department of Quality, Africa Improved Foods, Rwanda
}

Submission: June 12, 2017; Published: August 24, 2017

"Corresponding author : Rwamurangwa E, Department of Electrical, Electronics and Computer, University of Oviedo, Spain, Email: ing.rw.evode@gmail.com

\begin{abstract}
Mostly, electrical related parameters are capitally understood in energy and industrial like sectors; as a major issue specifically to find out how the sustainable and safe source of energy can be found. However, this battle is not only ending in finding out how to safeguard the energy need, but also touching the agricultural part; where electricity can be one of the tools used for a reliable post-havest handling. The paper in place will tackle the approach to use High Electric Field (HEF) to inhibit the growth of crop's harmful micro-organisms. It will look into the technical approach to design the electrical system, as well as its effective way of use to different storage systems. The Molds and aspyragellus will be the targeted micro-organism, and the crop of our focus will be Maize (Zea Mais) to avoid increase in aflatoxin.
\end{abstract}

Abbreviations: HEF: High Electric Field; PEF: Pulsed Electric Fields; ZVS: Zero-voltage Switching

\section{Introduction}

Cereals, maize especially, are capital source of carbohy-drates; They are one of the major stable crops consumed worldwide. Maize is used in various forms for home con-sumptions and animal feed. They make a bigger part of the raw material in food industries, and major part of export resources for many countries around the globe. Due, crops have to be critically controlled to meet the international standards. Mycotoxin development in many stored cereal grain has constantly affected the grains quality; the major source of the contamination for stored grains is the fungi: Aspergillus flavus and Aspergillus parasiticus; as they produce aflatoxin. The last is a kind of toxin, its levels on production was found to do not exceed an acceptable level limit of 50ppb stipulated in most export specifications [1]. Aflatoxin is mostly affecting maize and peanuts, it is a group of chemicals similar toxic fungal metabolites (mycotoxins) not affected by heat [2], and is the major source of Aflatoxicoses in humans and animals, and liver cancer among humans. It has been more prevalent in areas where maize constitutes a major part of the diet. Due, the researchers have been focused on identifying causal factors and formulating effective preventive and control measures against aflatoxin [1]. As it was previously shown, the aflatoxin is due to the growth of the fungi: Aspergillus flavus and Aspergillus parasiticus, as well as the molds. The paper in place will discuss the approach to inhibit the growth of the fungi: Aspergillus flavus and Aspergillus parasiticus using HEF. Most of the investigations into the bactericidal action of electric fields have been carried out at radio frequencies. In 1949 BURTON reviewed the literature, in which there are accounts both for and against the existance of bactrerial effects [3]. The HEF show some uncertainty concerning heat-ing effects, but non-thermal bactericidal effect occurs if high enough field is applied. The electric field generally can be used either Continuous or Pulsed. The working range of reported used field up to now is $2-50 \mathrm{kV}=\mathrm{cm}$ $[3,4]$. The Pulsed electric fields (PEF) is as well a non-thermal method of food conservation that uses short pulses of electricity for microbial inactivation and causes minimal detrimental effect on food quality attributes [4]. The electric field technology mostly PEF shows higher improvement on superiority compared to the traditional methods using thermal processing; as it shows good impact in avoiding or drastically reducing detrimental changes in tastes and physical properties of foods. The main objective of PEF is to provide high-quality foods to consumers. 
The PEF technology presents advantageous in comparison to: heat treatments, as it kills mirco-organisms without affecting the ariginal color, flavor, texture and nutritional value of the unprocessed food [4]. PEF in terms of High voltage is suitable to various medium of treatment, as it can be applied to liquids, semi-solid and solid foods between to electrified electrodes, here for instance there are: microbial inactivation in milk and milk products, egg products, juice and several liquid foods. This technology seems to be the most promising non-thermal method for food microbial inactivation; it is counted in the chosen range due to the type of microbes to inactivate. Due, the field intensity and the duration of the pulse can be chosen. In relation to PEF as a promissing non-thermal technology, several technologies were developed, for instance: oscillating magnetic fields, high hydrostatic pressure, light pulses, antimicrobials and bacteriocins [5].

This paper will illustrate the use of electricity as a remedy for post-harvesting, implementing the Electric field as a tool. The suitable prototype for the power supply, electric field generation and control will be tackled. And the general application of the whole system will be illustrated.

\section{Electricity and micro-organisms}

Electrical stimulation has been used as a modality for many years for wound healing. Due, one of the mechanisms proposed for why it works is that electrical stimulation is believed to be bacteria static [6]. In medicine, most of the cases of wound healing are really difficult to manage, for instance the wounds due to the diabetes. Several therapies were tried and failed. However, many papers point to the use of electrical stimulation across wound to accelerate healing. Some papers show wound healing with DC micro-current while others show only healing with AC currents [6]. Not only in medecine but also in food processing, where Electric fields and currents have been shown to be capable of desinfecting drinking water and reducing the numbers of bacteria and yeast in food. unfortunately, little research has been conducted regarding the effectiveness of electric fields and currents in the inactivation of viruses. Electric fields are themselves harmful to cells. It has been shown that this is primarily due to the irreversible permeablization of the cell membrane [7].

Fungi make an important group of micro-organisms, due to their positive biochemical abilities as starter cultures in biotechnology to positively modify food characteristics and stability; at the same time play an important role in the development of the products with economical importance. On the other hand, they contribute strongly on the spoilage of food and cause a serious economic issue, therefore the fungi control is drastically important. The use of electric field for microbial inactivation has received much attention in microbiology; Pulsed Electric Field (PEF), as food preservation method, has proved to inactivate the spoilage micro-organisms and pathogens [8]. The PEF application is based on switching for a short duration on
HEF to food product, which is placed between the two electrodes. The process succeeds only due to status of the cells morphology and physiology properties, the fluid medium properties, the type and characteristics of the used electric wave-form. From the discussions above, the research have touched almost all of the corners of microbes, as well as the way they are affected by HEF; the same way are the fungi source of aflatoxin.

\section{Principles of electric fields}

In order to have a better understanding of the High Electric Field, the attempt to review some basic electrostatic principles; among them, the Electric Field, is the capital point of the research in case. The electric field concept arose in an effort to explain action-at-a-distance forces. All charged objects create an electric field that extends outward into the space that surrounds it. The charge alters that space, causing any other charged object that enters the space to be affected by this field. The strength of the Electric Field is dependent upon how charged the object creating the field is and upon the distance of separation from the charged object.

$$
E=\frac{F}{Q}(1)
$$

From the eq.1, E being the electric field, $\mathrm{F}$ being the electrostatic force and $Q$ being the electric charge. The electric field is a vector quantity with force and direction for which units are Newtons per coulombs or volts per meter; thus defines the electric field. When we move one coulomb of charge from one point to another in an electric field, we do a work on that charge, due the electric potential.

$$
V_{a}-V_{b}=\int_{a}^{b} E . d s
$$

Volt can be also considered as the amount of work it takes to move one coulomb of charge a certain distance through an electric field E. This impliedly leads to capacitance; a capacitor is considered as two conductors separated by an insulator; the following illustrates its clear definition. The capacitance $\mathrm{C}$ of a capacitor is the ratio of the magnitude of the charge $Q$ on two bodies to the potential difference between the bodies [9].

$$
C=\frac{Q}{V}
$$

With C in Farads, Q in Coulombs, V in Volts, and the energy stored in a capacitor is as follow:

$$
W(\text { work })=\frac{C V^{2}}{2}
$$

From the Eq.2, let the distance from a to $\mathrm{b}$ be called $\mathrm{d}$ and $\mathrm{Va}$, $\mathrm{Vb}=\mathrm{V}$, the the Eq.2 will become as follow:

$$
V=E . d
$$

Considering the Eq.5, the applied DC voltage to certain parallel plates forms a proportional electric field on a fixed distance between the plates. The DC voltage applied here will work as a control parameter. It is with that voltage, that the 
pulsating signal is generated. To insure the right amount of electric field applied, the applied voltage has to be consistently monitored. Here the accurate design of the high voltage DC measuring circuit is implicated. Therefore, the facilitating parameter will be the electrostatic force illustrated in Eq.1. Considering the equations Eq.4, the energy stored in the formed capacitor between the two electrodes is illustrated. The changes that can occur in the energy are showed in Eq.6.

$$
d W=\frac{1}{2} v^{2} d c=F d X
$$

If we consider $\mathrm{X}$ to be the spacing between the electrodes or plates. Due, the force will be as

$$
\begin{gathered}
F=\frac{1}{2} V^{2} \frac{d c}{d X}(7) \\
C=\frac{A \varepsilon}{X} \\
\frac{d c}{d X}=-\frac{A \varepsilon}{X^{2}}
\end{gathered}
$$

From the equations Eq.8 and Eq.9, the force F can be found

$$
F=-\frac{1}{2} A \varepsilon \frac{V^{2}}{X^{2}}
$$

From the equation Eq.10, the force is proportional to the square of the potential difference. Due, the potential difference can be monitored through monitoring the force. As the voltage from the sending end will be kept varying to identify the suitable field, based on the application, its values will be continuously monitored through the force measuring. The rest of the work will be to find a way of safe and high voltage application, with the optimum energy density.

\section{Approach to the Prototype Design}

In order to achieve reliable results of the research in place, the High Electric Field is needed, this implies High voltage DC. The last as far as energy density and safety are concerned, the design is needed. An adaptive and flexible voltage source is required. To make such flexibility, the source of power will have to be controlled. Reminding back here that the control parameter the field needs is voltage. Due, the voltage in turn has to be controlled and adapted to that high flexibility. The maximum energy density is achieved by tremendously reducing the equipment size without reducing the power capability. The system safety is reached by isolating different steps of the equipment. The three requirements above are achieved by using resonant converters; as they provide flexibility to work at high frquencies, with controllable switching losses and high conversion gain.

The resonant converters are made of voltage source (mostly DC), controlled inverter, resonant tank, transformer, full-wave rectifier, and the load. The resonant tank can be either parallel or series, and each of the structures has its own advantages and drawbacks [10]. As the resonant tank has dynamic behavior based variability of the frequency; the last can even help in reducing the components to use in the building the prototype. The components of the resonant tank can be found considering the parasitics of the transformer. Hence, the total size decreases, and energy density increases. The switching losses can be controlled in Zero-voltage switching (ZVS) mode of functionality [10]. From the Figure 1, the power supply circuit is illustrated; together with Ls and $\mathrm{Cp}$ the transformer parasitic. The architecture in Figure 1 fulfill the advantageous configuration discussed in $[11,12]$. The proper modulation for switching of the controlled inverter, the range of frequencies to be used and the whole analysis behind will be following the discussions in [11]. Hence the controlled high voltage DC is generated. The prototype is safe, as the power source and the output end are on different grounds, the transformer makes a nice isolation. The power density is achieved, as longer as the switching frequency is high, the size of the components will be smaller at higher voltage. Following the Eq.5, the conducting probes will be connected to positive and negative terminal respectively, the distance $d$ between this made fixed, the required voltage is applied, hence the Electric Field, the last is high following the amplitude of the generating voltage. From the discussions above, the prototype will be build specifically following the fungi: Aspergillus flavus and Aspergillus parasiticus condition of growth, in order to be able to destroy it in maize crops.

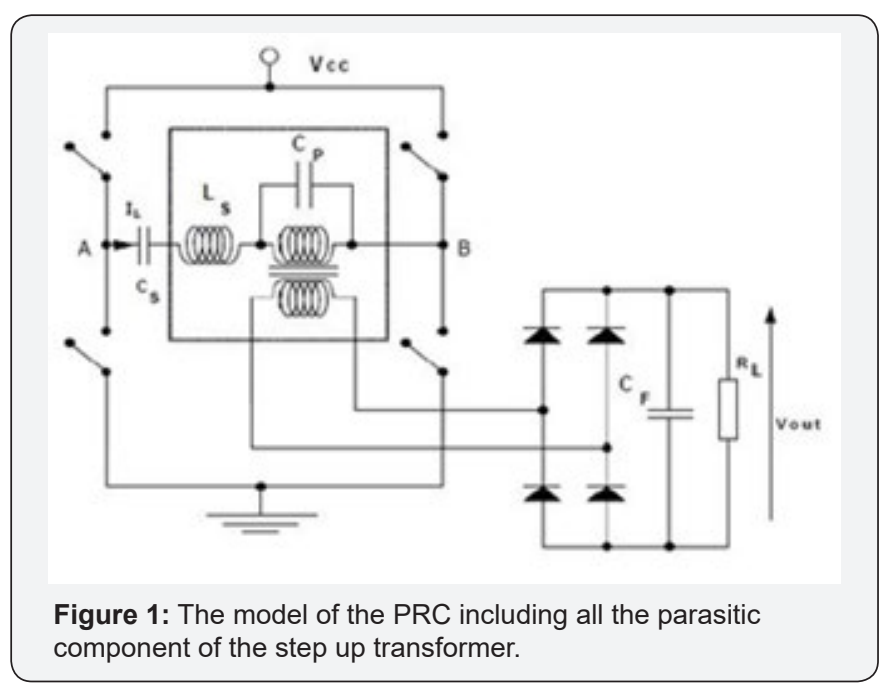

\section{Principles of Application}

Micro-organisms are inactivated when they are exposed to factors that substantially alter their cell structure or physiological functionality. Cell functions are altered when the membrane of selectivity is disablaed [13]. Membrane structural or functional damage is generally accepted as the cause of cell death during exposure to High-voltage Electric Field. The best way of exposing the micro-organisms to the High-voltage Electric Field depend on the application in place. Generally, the flexible electric field will be generated, at the required intensity, then it will be aimed 
to the micro-organisms environment. Here we can state two among the possible environment: Static storages and Dynamic flow of material (Figure 2).

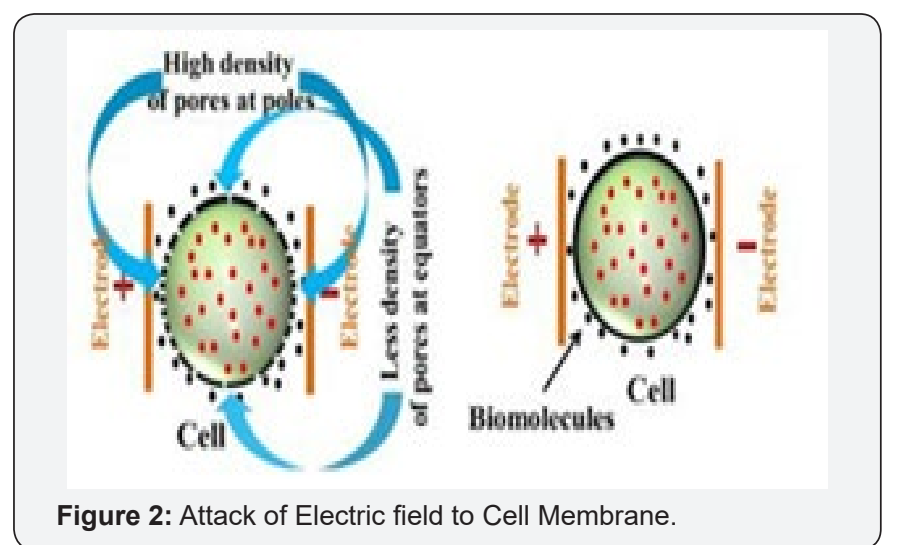

\section{Static storage exposure}

This is the in-process storage where the material can take hours kept, and there is high chance of micro biological growth and contamination. This environment can be a silo or a bin. The material inside will be exposed to a suitable electric field intensity. The material in the static state, and exposed to specific electric field intensity, then the existing micro-organisms will die and no new ones will be able to grow. From the Figure 3, the two charged electrodes are place on both sides of the stored material, and the field lines will be going through the storage.

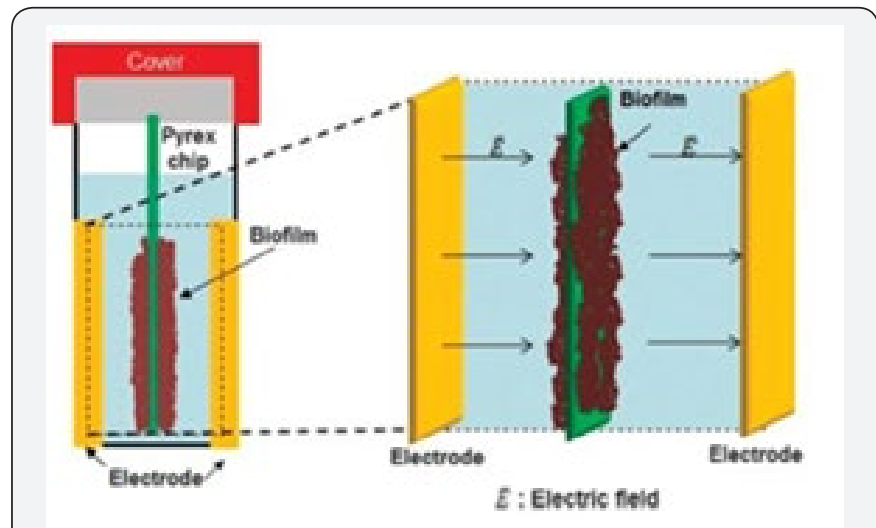

Figure 3: Illustrations of the static storage exposure.

\section{Dynamic flow of material}

On the other hand, the material can be in movement instead, and can get contaminated in that route. This is the case when product is under process; in the last, the decontaminants can be applied in process line. The points will be chosen in different routes, on which the electric field will be applied. From the determined using the immune chemical methods (Figure 3) [14]. This will help to ascertain the Pulsed Electric Field on the levels of aflatoxin in maize grains during storage.

\section{Conclusion}

In conclusion, the issues of the aflatoxin due, to the growth of the fungi: Aspergillus flavus and Aspergillus parasiticus; which is the great attack to the maize harvest and a capital handicap of the economy has been discussed. The use of electric Field either pulsed or continuous at high intensity was proposed, and considered as promising technology, taking into account different and possible applications. From different discussions, Electric field looks to be the best way to fight aflatoxin. The only remaining part is to find a suitable, safe and generic way of application, which is the way forward. Figure 4, the treatment chamber can be created at the end of each product rout.

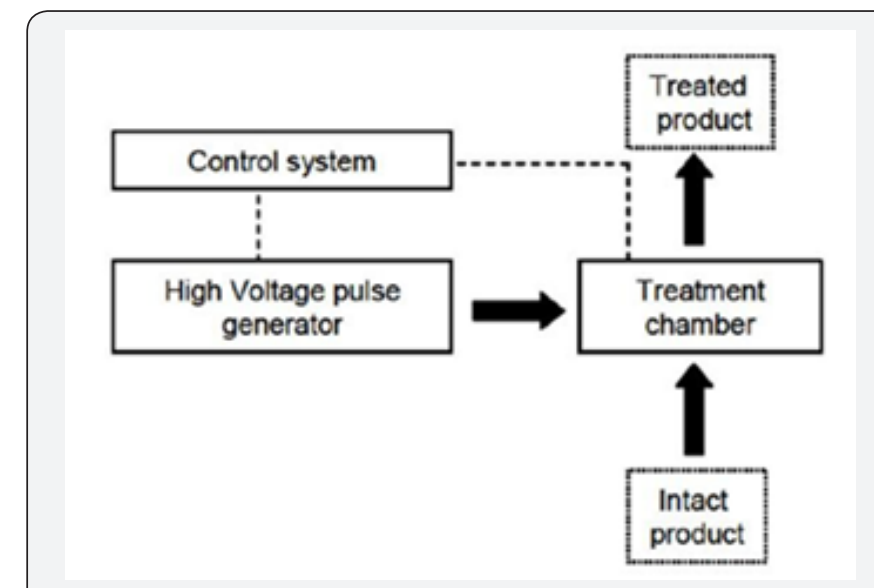

Figure 4: The illustration of the Dynamic flow of material.

\section{Effect of PEF on microorganisms}

Molds are fungi whose growth is favored by production of hyphae responsible for colonizing the grain [15]. To determine the effect of PEF on mold growth, the levels of micro-organism in maize before application of PEF needs to be determined. The mold levels can then be determined after the application of PEF. The enumeration of molds can be done following the method according to general guidance for enumeration of yeasts and molds [16]. Till today no clear mechanism is available to explain the inactivation for the exposed biological cells to Pulsed Electric Fields. The micro organisms inactivation by PEF is multi-step process which may cause cell death through multi-mechanisms, the four stages are considered:

A. Increase in trans membrane potential due to charging the cell plasma membrane by external electric field applied.

\section{B. Pore initiation stage.}

C. Evolution of the pore population during an electric treatment and

D. Post-treatment stage (pore resealing, cell death) [8]. Primarily, the effects of PEF on microbial cells depend on the pulse amplitude and cell size and including structural fatigue due to induced membrane potential and mechanical stress [17-19]. The whole duration for this is in the range of nanoseconds to milliseconds, on all type of micro-organisms; either spherical, spheroidal, ellipsoidal, cylindrical or the cell with irregular form. Since the molds are the main producers of aflatoxin, the levels of total aflatoxin can be monitored before the application of PEF and later. 


\section{References}

1. Mycotoxin prevention and control in foodgrains.

2. Richard L (2013) Aflotoxins.

3. Sale A, Hamilton W (1967) Effects of high electric fields on micro organisms: I. killing of bacteria and yeasts. Biochimica et Biophysica Acta (BBA)-General Subjects 148(3): 781-788.

4. Mohamed ME, Ayman H, Eissa A (2012) Pulsed electric fields for food processing technology. In: Eissa AA (Ed.), INTECH Open Access Publisher, Croatia.

5. Zhong K, Chen F, Wu J, Wang Z, Liao X, et al. (2005) Kinetics of inactivation of escherichia coli in carrot juice by pulsed electric field. Journal of food process engineering 28(6): 595-609.

6. Petrofsky J, Laymon M, Chung W, Collins K, Yang TN (2008) Effect of electrical stimulation on bacterial growth. J Orthop Neurolsurg 31: 43.

7. Drees KP, Abbaszadegan M, Maier RM (2003) Comparative electrochemical inactivation of bacteria and bacteriophage. Water research 37(10): 2291-2300

8. Stoica M, Bahrim G, Carac G Factors that influence the electric field effects on fungal cells. Science against microbial pathogens: communicating current research and technological advances pp. 291302

9. Vosteen WE (1984) A review of current electrostatic measurement techniques and their limitations. In Electrical Overstress Exposition pp. 24-26.

10. Choi H, Team PC (2007) Design considerations for an llc resonant converter. In Fairchild Power Seminar pp. 82-83.
11. Rwamurangwa E (2015) High voltage measuring circuits in ac/dc converters for e-beam welding machines.

12. Biela J, Kolar JW (2005) Using transformer parasitics for resonant converters-a review of the calculation of the stray capacitance of transformers, in Industry Applications Conference, 2005. Fourtieth IAS Annual Meeting Conference Record of the IEEE, China 3: 1868-1875.

13. Lado BH, Yousef AE (2002) Alternative food-preservation technologies: efficacy and mechanisms. Microbes and Infection 4(4): 433-440.

14. Wacoo AP, Wendiro D, Vuzi PC, Hawumba JF (2014) Methods for detection of aflatoxins in agricultural food crops. Journal of Applied Chemistry 2014.

15. Stack JP (2000) Grain molds and mycotoxins in corn. Cooperative Extension, Institute of Agriculture and Natural Resources, University of Nebraska-Lincoln, USA.

16. Bird P, Flannery J, Crowley E, Agin J, Goins D, et al. (2015) Evaluation of the 3mâđ petrifilmâđ rapid yeast and mold count plate for the enumeration of yeast and mold in food: Collaborative study, first action 2014.05. Journal of AOAC International 98(3): 767-783.

17. Min S, Evrendilek GA, Zhang HQ (2007) Pulsed electric fields: processing system, microbial and enzyme inhibition, and shelf life extension of foods. IEEE Transactions on Plasma Science 35(1): 59-73.

18. Santra TS, Tseng FG (2013) Recent trends on micro/nanofluidic single cell electroporation. Micromachines 4(3): 333-356.

19. Kim YW, Subramanian S, Gerasopoulos K, Ben-Yoav H, Wu HC, et al (2015) Effect of electrical energy on the efficacy of biofilm treatment using the bioelectric effect. Npj Biofilms and Microbiomes 1: 15016.

This work is licensed under Creative

Commons Attribution 4.0 License

DOI: $10.19080 / A R T O A J .2017 .10 .555786$
Your next submission with Juniper Publishers will reach you the below assets

- Quality Editorial service

- Swift Peer Review

- Reprints availability

- E-prints Service

- Manuscript Podcast for convenient understanding

- Global attainment for your research

- Manuscript accessibility in different formats

( Pdf, E-pub, Full Text, Audio)

- Unceasing customer service

Track the below URL for one-step submission https://juniperpublishers.com/online-submission.php 